\title{
Sinterização por plasma de arcabouços porosos da liga Ti-Sn- $\mathrm{Nb}_{2} \mathrm{O}_{5}$
}

\author{
Plasma sintering of porous scaffolds of $\mathrm{Ti}-\mathrm{Sn}-\mathrm{Nb}_{2} \mathrm{O}_{5}$ alloys \\ Marina de Oliveira Cardoso Macedo ${ }^{1}$, Haroldo Reis Alves de Macêdo², \\ Natália Freitas Daudt ${ }^{1}$, Clodomiro Alves Júnior ${ }^{1}$
}

\begin{abstract}
Resumo
Os arcabouços são materiais promissores para aplicações biomédicas. Esse tipo de material tridimensional possui propriedade osteocondutora. Entretanto o uso de titânio puro, para a produção desses arcabouços torna esse artefato caro e consequentemente inacessível a uma ampla camada da população. Por isso o titânio tem sido utilizado em associação com outro elementos como molibdênio (Mb), Tântalo (Ta), Zircônia (Zr), Estanho (Sn) e Nióbio (Nb). Dentre as ligas utilizadas destaca-se a de Ti-Sn-Nb por apresentar excelente biocompatibilidade. Vários métodos têm sido investigados para a produção desses arcabouços, incluindo a técnica de metalurgia do pó. Neste trabalho arcabouços de ligas de titânio (Ti-Sn- $\mathrm{Nb}_{2} \mathrm{O}_{5}$ ) foram produzidos a partir da sinterização por plasma, com a finalidade de obter um material com uma superfície porosa e um núcleo denso, sem a necessidade de usar esparçantes para a formação dos poros, a fim de utiliza-los como biomaterial. As amostras foram caracterizadas por microscopia óptica, microscopia eletrônica de varredura e análise de imagem e absorção. A amostra 1 apresentou uma camada superficial com alta porosidade $(56,42 \%)$ denominada de camada porosa ou zona de bombardeamento, depois dessa camada há uma diminuição da porosidade. Em relação ao núcleo este, apresenta-se mais denso com porosidade de $7,44 \%$. O arcabouço A3 apresentou uma alta porosidade tanto na superfície $(66,83 \%)$ como no núcleo $(58,80 \%)$. Os tamanhos de poros encontrados nas amostras variaram de menor que $10 \mu \mathrm{m}$ e acima de $150 \mu \mathrm{m}$. o arcabouço A1 apresentou maior dureza ( $282,9 \mathrm{Hv}$ ) e o arcabouço A3 menor dureza (210,14 Hv). Quanto ao teste de absorção o arcabouço A3 absorveu mais rápido do que o arcabouço A1, em 10 segundos. Durantes as análises de MEV - EDX constatou-se a presença de titânio, nióbio, estanho e oxigênio.
\end{abstract}

Palavras-chave: Sinterização; Plasma; Titânio.

\begin{abstract}
The scaffolds are material promising for biomedical applications. That type of three-dimensional material possesses properties osteoconductive. However the use of pure titanium for the production of these scaffolds makes this artifact expensive and thus inaccessible to a wide range of people. That is why titanium has been used in combination with other elements such as molybdenum (Mb), tantalum (Ta), zirconium ( $\mathrm{Zr}$ ), tin (Sn) and niobium (Nb). Among the most prominent leagues has the Ti-Sn-Nb because of their excellent biocompatibility. Several methods have been investigated for the production of those scaffolds, including the technique of metallurgy of the powder. In this work scaffolds titanium alloys (Ti-Sn-Nb $\mathrm{O}_{2}$ ) were produced from the sintering process, in order to obtain a material with a porous surface and a dense core, without the need to use space-holder for the formation of pores in order to use them as a biomaterial. The samples were characterized by optical microscopy, electronic microscopy of scanning and image analysis and absorption. The sample 1 presented a superficial layer with high porosity $(56,42 \%)$ denominated of porous layer or bombardment area, after that layer there is a decrease of the porosity. In relation to the nucleus this, comes denser with porosity of 7,44\%. The sample A3 presented a high porosity so much in the surface $(66,83 \%)$ as in the nucleus $(58,80 \%)$. The sizes of pores found in the samples varied of minor that $10 \mu \mathrm{m}$ and above $150 \mu \mathrm{m}$. the sample A1 presented larger microhardness $(282,9 \mathrm{Hv})$ and the sample $\mathrm{A} 3 \mathrm{smaller}$ microhardness $(210,14 \mathrm{Hv})$. The absorption test the sample $A 3$ absorbed faster than the sample A1, in 10 seconds. During the analyses of MEV -EDX was verified the presence of titanium, niobium, tin and oxygen.
\end{abstract}

Keywords: Sintering; Plasma; Titanium. 


\section{Introdução}

Suportes porosos de titânio, os denominados arcabouços são materiais promissores para aplicações biomédicas. Esse tipo de material tridimensional possui propriedades osteocondutora, ou seja, facilita a migração de osteoblastos em torno do local do implante ajudando assim o processo de cicatrização ${ }^{(1)}$.

Arcabouços de titânio têm sido usados para facilitar e/ou permitir o crescimento ósseo na estrutura porosa. Este crescimento ósseo fornece uma forte interação entre o implante e o tecido ósseo. Os poros devem ser preferencialmente interligados tridimensionalmente para fornecer espaço suficiente para a fixação e proliferação de tecido ósseo novo e para facilitar o transporte de fluidos pelo material. Estas estruturas porosas têm muitas aplicações que vão desde próteses de quadril acetabular, implantes dentários, placas de osteossíntese permanente, e os discos invertebrais ${ }^{(2)}$.

Entretanto o uso do titânio puro, para a produção desses arcabouços torna esse artefato caro e, consequentemente, inacessível a uma ampla camada da população. Por isso o titânio tem sido utilizado em associação com outros elementos como molibdênio, tântalo, zircônia, estanho e nióbio. Dentre as ligas de maior destaque tem-se a de Ti-Sn- $\mathrm{Nb}_{2} \mathrm{O}_{5}$ por apresentar excelente biocompatibilidade ${ }^{(3)}$.

Essas ligas devem ser biocompatíveis, possuir alta resistência mecânica, baixo módulo de elasticidade, pois não pode ser tão rígida a ponto de não acompanhar a flexibilidade do osso. O elevado módulo de elasticidade limita as deformações naturais do fêmur, o que pode causar degeneração óssea ${ }^{(3)}$.

Vários métodos têm sido investigados para a produção desses arcabouços, incluindo a técnica de metalurgia do pó, que parece ser particularmente vantajosa por causa de sua rota de processamento e custo. Na metalurgia do pó, os poros dependem da compactação das partículas, da decomposição de partículas esparçantes que provoca o aumento da porosidade e da difusão no estado sólido na etapa de sinterização ${ }^{(4)}$.

Uma técnica que tem mostrado resultados significantes para a produção desses arcabouços é a sinterização por plasma. Trabalhos realizados revelaram que amostras sinterizadas por plasma apresentaram gradiente de porosidade entre a superfície em contato com o plasma e o núcleo das amostras ${ }^{(5)}$.

Quando um material é imerso em plasma está exposto a um ambiente complexo, onde a superfície do material irá ser influenciada principalmente pela radiação e pelo bombardeamento das espécies iônicas, sendo esse último responsável pelos picos térmicos. Os picos térmicos por sua vez, provocarão aquecimentos pontuais de alta intensidade modificando localmente a estrutura do material ${ }^{(6)}$. Tem-se que a intensidade da porosidade na superfície do material varia de acordo com os parâmetros dos sistemas tais como pressão e configuração de eletrodos ${ }^{(7)}$.

A camada do material afetada por bombardeamento foi denominada como zona de afetada pelo bombardeamento $-\mathrm{ZAB}^{(7)}$. Em tratamentos térmicos de materiais maciços a ZAB apresenta-se como uma microestrutura distinta do resto da amostra, e na sinterização de materiais porosos essa camada apresenta-se com uma porosidade maior que o resto da estrutura do material ${ }^{(7)}$.

Neste trabalho arcabouços de ligas de titânio (Ti-Sn- $\mathrm{Nb}_{2} \mathrm{O}_{5}$ ) foram produzidos a partir da sinterização por plasma, com a finalidade de obter um material com uma superfície porosa e um núcleo denso, sem a necessidade de usar esparçantes para a formação dos poros e um núcleo, sem a necessidade de usar esparçantes para a formação dos porosos, a fim de utiliza-los como biomaterial.

\section{Experimental}

Os seguintes materiais, titânio (Ti-90 e 80), estanho ( $\mathrm{Sn}-5,10$ e 15) e óxido de nióbio $\left(\mathrm{Nb}_{2} \mathrm{O}_{5}-5,10\right.$ e 15) (\% em peso) na forma de pó, foram usados na preparação dos arcabouços de ligas de Ti, como mostra a Tabela 1.

Tabela 1. Composição das amostras.

\begin{tabular}{|c|c|c|}
\hline Nomenclatura & Símbolos & Composição em peso \\
\hline Amostra 1 & A1 & $90 \% \mathrm{Ti}-5 \% \mathrm{Sn}-5 \% \mathrm{Nb}_{2} \mathrm{O}_{5}$ \\
\hline Amostra 3 & A3 & $80 \% \mathrm{Ti}-5 \% \mathrm{Sn}-15 \% \mathrm{Nb}_{2} \mathrm{O}_{5}$ \\
\hline
\end{tabular}

Para o processo de sinterização por plasma (cátodo oco), os pós foram misturados e compactados para obtenção das amostras verde, foi utilizado um molde e uma prensa hidráulica, a carga aplicada sobre o molde foi de 13 toneladas durante 30 segundos. A sinterização foi realizada a $900^{\circ} \mathrm{C}$ durante 2 horas sob atmosfera de argônio (Ar) e hidrogênio $\left(\mathrm{H}_{2}\right)$.

O reator de plasma para a sinterização das amostras de liga de Ti consiste em uma câmara de vidro borossilicato com formato cilíndrico, possuindo dois eletrodos nas 
extremidades. A câmara é equipada com termopar, bomba de vácuo, sensor de pressão, fonte de corrente contínua e o sistema de alimentação de gases (Fig. 1). Em todas as sinterizações foi usado fluxo total de $20 \mathrm{sccm}(17 \mathrm{sccm}$ de $\operatorname{Ar}$ e $3 \mathrm{sccm}$ de $\mathrm{H}_{2}$ ) com pressão de 6 mbar.

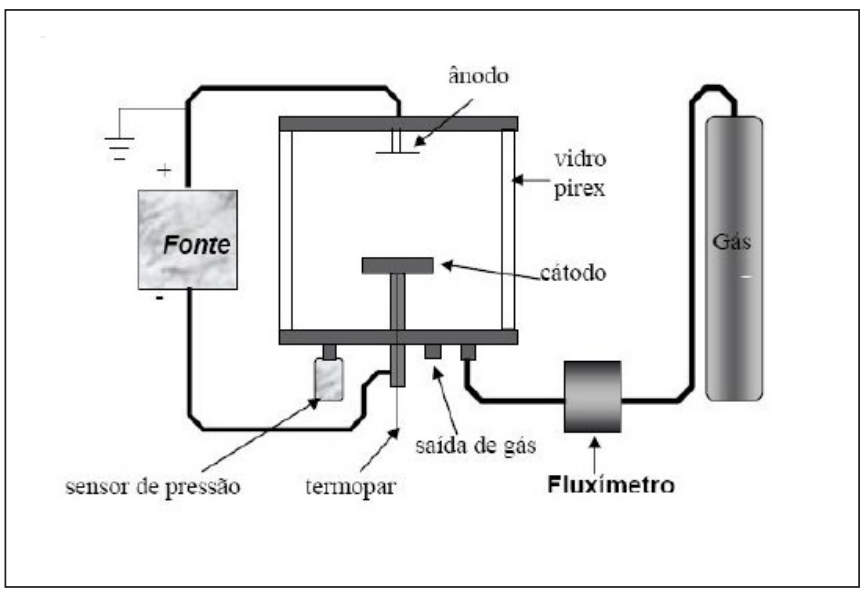

Figura 1. Esquema do reator de plasma utilizado para a sinterização.

No processo de sinterização foi utilizada a configuração de cátodo oco, no qual as amostras ficaram posicionadas, entre os cátodos, aumentando assim a eficiência do tratamento. O modelo do cátodo oco usado no trabalho é um anteparo de forma circular de $35 \mathrm{~mm}$ de diâmetro suspenso por um tripé. Este foi confeccionado em aço inox com altura de $6 \mathrm{~mm}$ em relação à superfície e o teto do cátodo (Fig. 2).



Figura 2. configuração do cátodo oco utilizada neste trabalho.

As amostras após serem sinterizadas foram submetidas ao processo metalográfico de lixamento (Lixas variando de 220 a 200 mesh) e polimento (solução de sílica coloidal com peróxido de hidrogênio).
Para análise de imagens foi utilizado o microscópio OLYMPUS BX60M, equipado com uma câmera de aquisição de imagem. As imagens foram analisadas com auxilio do software Image ProPlus 6.0.

O cálculo da porcentagem de porosidade foi realizado da seguinte forma: Primeiro a imagem foi dividida em duas regiões de análise - borda e núcleo- em seguida foi calculado a porosidade em cada uma dessas regiões. A soma da área porosa total foi dividida pela área total da região analisada e multiplicada por 100 para obtenção de valores em porcentagem. Além disso, foi possível também medir a espessura da camada porosa e observar a presença ou não de interconectividade dos poros, para isto utilizou-se um microscópio de varredura Philips XL-30-ESEM (MEV).

Para ensaios de microdureza Vickers das amostras sinterizadas e polidas, foi utilizado o equipamento da marca Panambra modelo HVS 1000, utilizando uma carga de 50g, por um tempo de 15 segundos. As medidas foram feitas de uma borda a outra da amostra passando pelo núcleo, com espaçamento de $250 \mu \mathrm{m}$ entre as medidas. Observando assim a diferença de microdureza entre o centro e a borda.

\section{Resultados e Discussão}

Amostras tratadas por plasma apresentaram diferentes graus de porosidade para as diferentes composições. O arcabouço A1 apresentou uma camada superficial com alta porosidade $(56,42 \%)$ denominada de camada porosa ou zona de bombardeamento, depois dessa camada há uma diminuição da porosidade. Em relação ao núcleo este, apresenta-se mais denso com porosidade de $7,44 \%$ (Fig. 3 ).

A área que apresenta a maior porosidade é denominada $\mathrm{ZAB}$, onde ocorre o maior bombardeamento das partículas com o material formando assim um material de superfície porosa e um núcleo mais compacto ${ }^{(7)}$. Comparando a amostra 1 com a amostra 3 , a quantidade de Sn permaneceu a mesma, mas houve uma diminuição da quantidade de Ti e aumento de $\mathrm{Nb}_{2} \mathrm{O}_{5}$, com isso o material apresentou uma alta porosidade tanto na superfície $(66,83 \%)$ como no núcleo $(58,80 \%)$ (Fig. 4).

Em relação à espessura da camada porosa presentes nas amostras estas variaram tanto em relação à quantidade de material usado em cada amostra, como em relação ao lado que ficava em contato com o porta amostra e o lado do plasma. $\mathrm{O}$ arcabouço A1 a camada porosa apresentou-se mais espessa 
do lado do plasma do que do lado do porta amostra como mostra a Fig. 5.

Em relação à amostra $\mathrm{A} 3$, esta não apresentou uma camada porosa superficial em destaque como no arcabouço

(a)

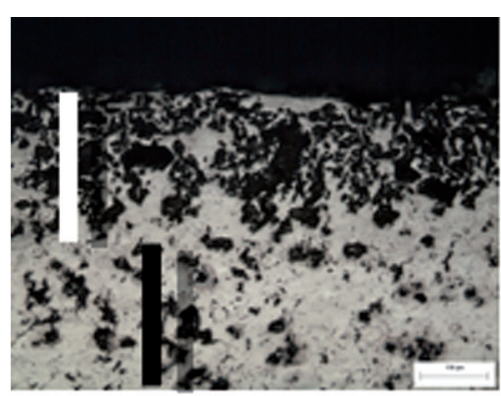

(b)

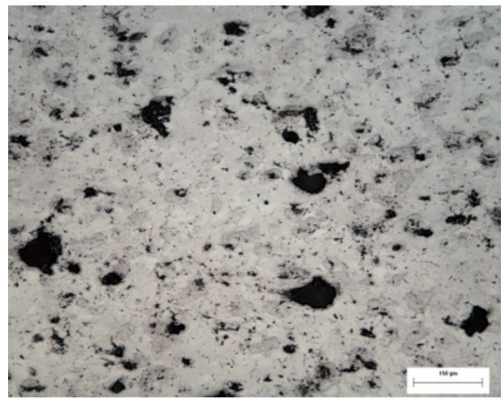

Figura 3. Na Fig. a (aumento 200x) tem-se a imagem da borda da A1, a área sinalizada pela barra branca, é denominada de camada porosa, na área sinalizada pela barra preta à porosidade encontrada foi de $18,13 \%$. Na Fig. b (aumento 200x) o núcleo da amostra.



Figura 4. Fig. a (aumento 200x) borda da amostra, onde, observa-se um aumento de porosidade em relação à amostra 1 . Fig. b (aumento 200x) núcleo da amostra apresenta-se bastante poroso sem grandes diferenças de porosidade entre a borda e o núcleo.
A1, não sendo, portanto possível medir essa camada (Fig. 6).

Através da microscopia eletrônica de varredura (MEV) também foi possível verificar a existência de

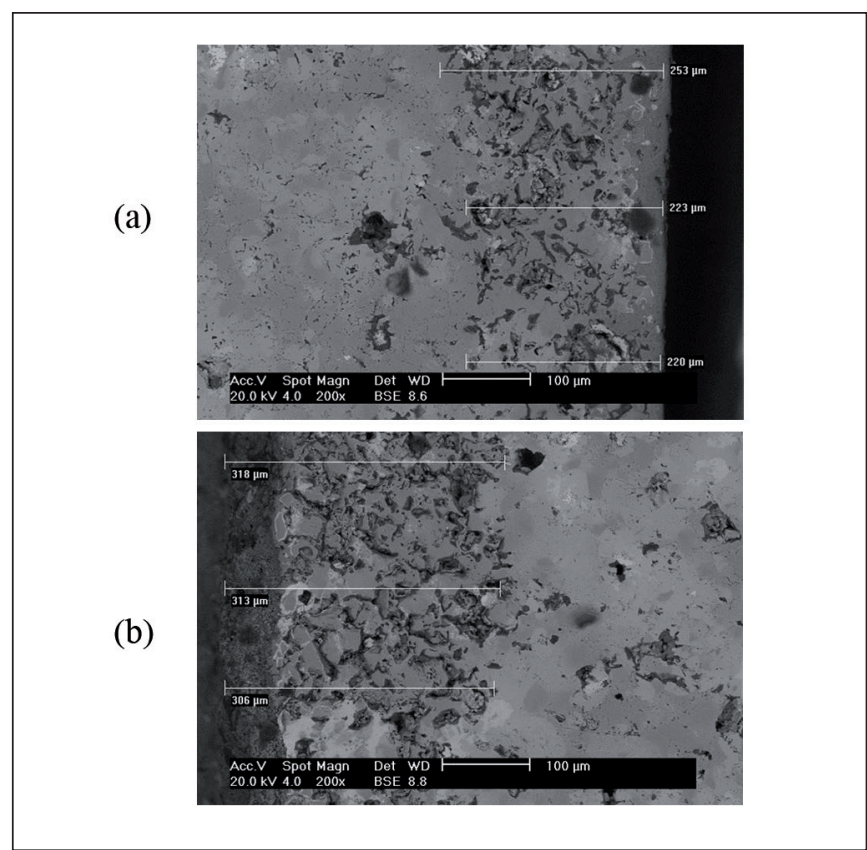

Figura 5. Medição da espessura da camada porosa através de microscopia eletrônica de varredura da A1. A Fig.a mostra o lado que ficou em contato com o porta amostra e a Fig. $b$ mostra o lado voltado para o plasma, ou seja, a zona afetada pelo bombardeamento (ZAB)

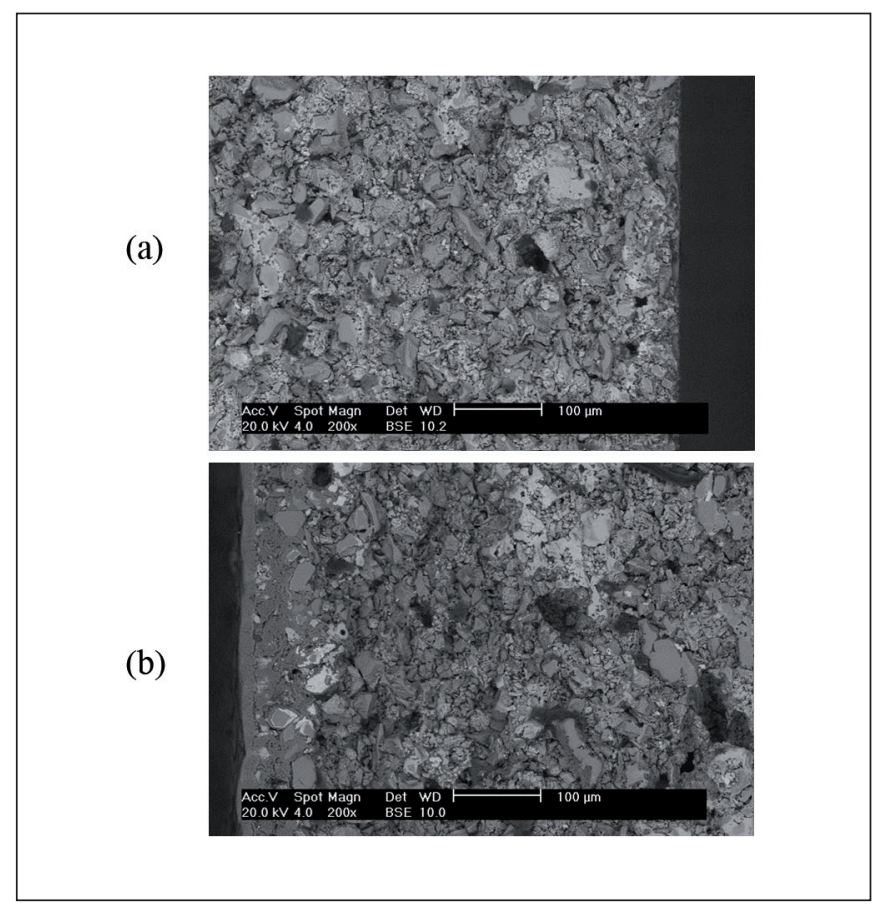

Figura 6. Fig. a lado do porta amostra e Fig. b lado do plasma. 
interconectividade entre os poros existentes nas amostras. No arcabouço A1 foi possível confirmar a interconectividade entre os poros (Fig.7). No arcabouço A3 também houve formação de poros, entretanto observou-se que muito dos poros formados eram por conta da não desnsificação completa das partículas em função da grande concentração de óxido de nióbio (Fig. 8).

A porosidade e a interconectividade dos poros nas amostras é importante, pois pode permitir o ancoramento

(a)

(b)

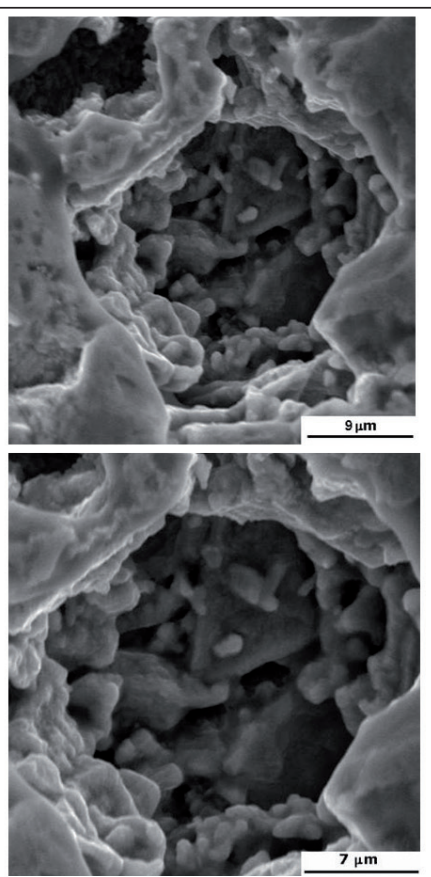

Figura 7. Fig.a- visão geral do poro do arcabouço A1, com aumento de 3500x, Fig.b - visão interna do poro, mostrando outros poros em seu interior, aumento de 5000x.

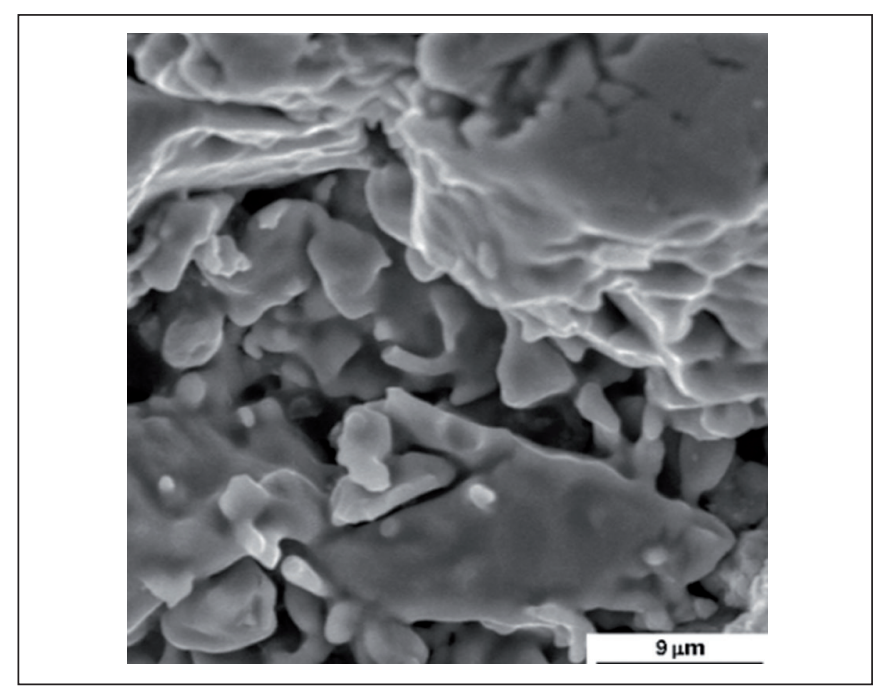

Figura 8. Poros encontrados no arcabouço A3 com aumento de $3500 x$ mecânico do biomaterial no local a ser implantado e promover o crescimento celular, bem como induzir as células a produzirem componentes da matriz extracelular ${ }^{(8)}$.

Nos ensaios de microdureza, houve grandes diferenças entre a borda e o núcleo das amostras. A Fig.9 apresenta a microdureza da borda das amostras, observa-se que a borda do arcabouço A1 com maior quantidade de $\mathrm{Ti}(90 \%)$ possui maior dureza do que o arcabouço A3 que possui menor quantidade de $\mathrm{Ti}(80 \%)$. Outra observação a ser feita a respeito do gráfico é que quanto maior for à proporção de óxido de nióbio menor é a dureza da borda.

Nos ensaios de microdureza do núcleo (Fig. 10), as amostras tiveram um comportamento semelhante do encontrado na Fig. 9, entretanto houve uma diminuição da dureza do núcleo

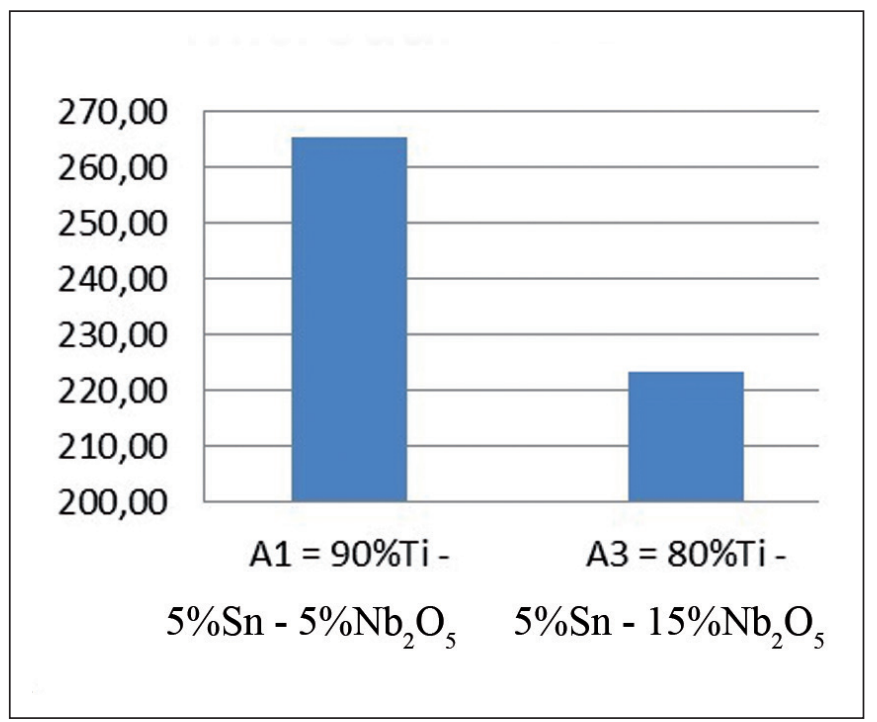

Figura 9. Perfil da microdureza da borda das amostras

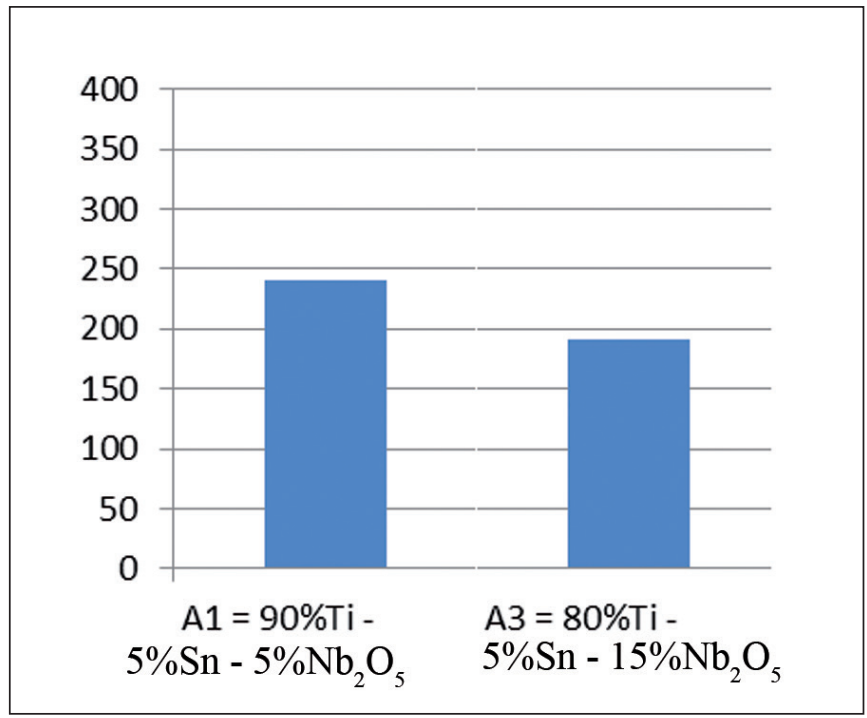

Figura 10. Perfil da microdureza do núcleo das amostras sinterizadas. 
do arcabouço A1 e um aumento da dureza do núcleo do arcabouço $\mathrm{A} 3$ em relação à dureza da borda.

Quanto aos ensaios de absorção a amostras A3 demorou menos tempo em absorver a gota de água colocada sobre a superfície da mesma com auxilio de um goniômetro, apenas 10 segundos enquanto que o arcabouço A1 demorou 110 segundos para absorção completa da gota.

Isso aconteceu devido à diferença de porosidade entre as duas amostras como dito anteriormente, na apresentação dos resultados de porosidade.

Durante as análises de MEV - EDX constatou-se a presença de titânio (L-K), nióbio(L), estanho (L) e oxigênio (K) (Fig. 12). Comparando-se os dois gráficos observa-se um aumento do pico de nióbio e oxigênio no gráfico b, constando-se a proporção maior de óxido de nióbio presente no arcabouço A3.

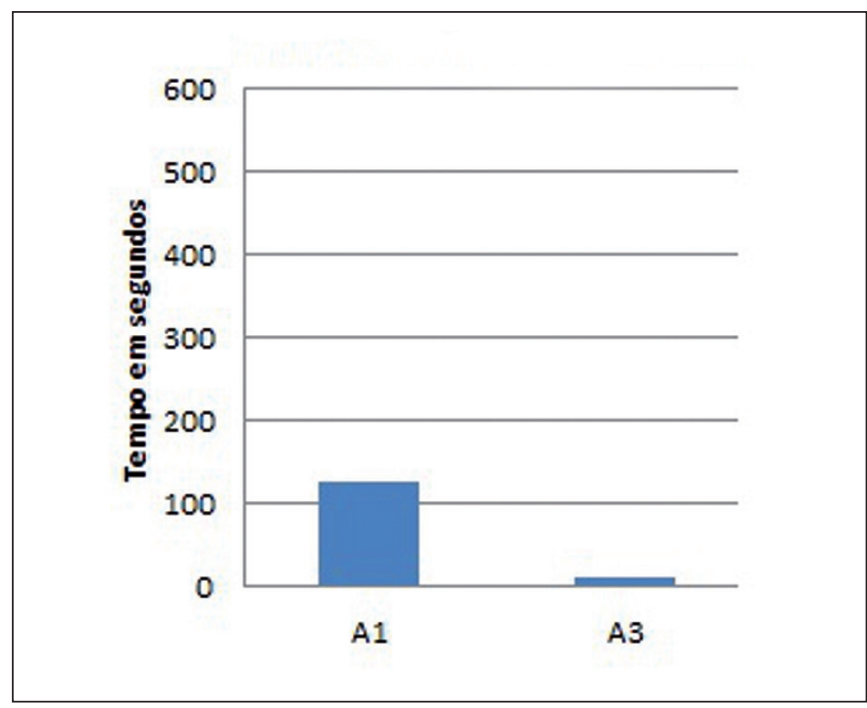

Figura 11. Ensaio de absorção com água destilada nas amostras A1 e A3.

(a)

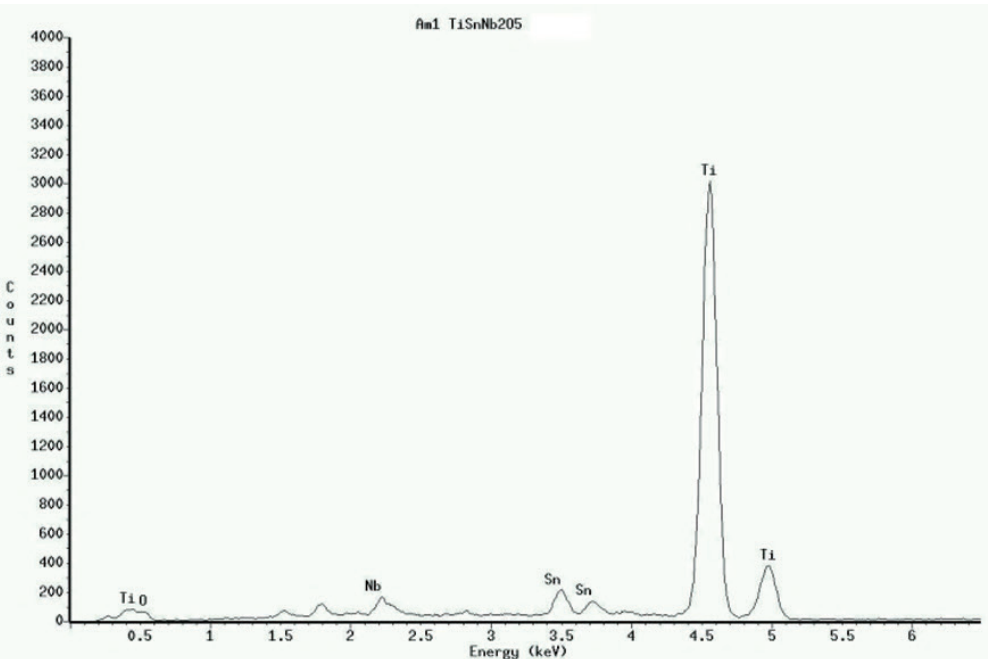

(b)

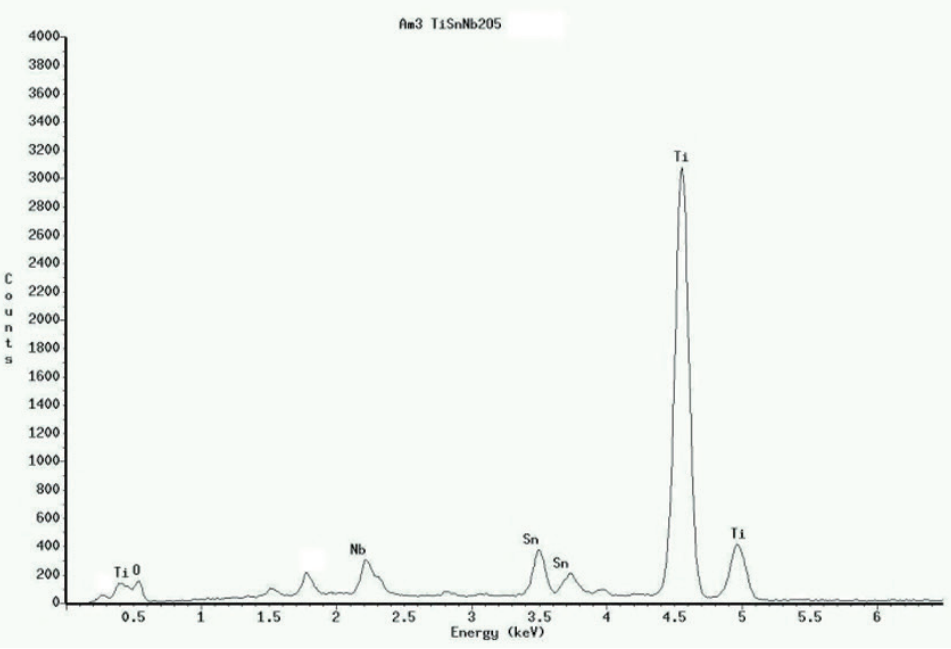

Figura 12. Composição das amostras por EDX. Fig.a - amostra A1, Fig.b amostra A2. 


\section{Conclusão}

A sinterização por plasma em cátodo oco foi eficiente para a produção de peças com uma superfície mais porosa e um núcleo mais denso. Além disso, foi possível obter amostras com interconectividade entre os poros, essas interconexões favorecem a formação de tecidos na forma de uma rede organizada, tendo grande aplicação na reconstrução tecidual. As proporções dos elementos $\mathrm{Sn}$ e $\mathrm{Nb}_{2} \mathrm{O}_{5}$ utilizados para a produção destes arcabouços de ligas de Ti influenciaram na porosidade do material, na dureza e absorção de água. Quanto maior a proporção de $\mathrm{Nb}_{2} \mathrm{O}_{5}$ mais porosa e frágil é a amostra.

\section{Agradecimentos}

UFRN, Capes, CNPq, Labplasma.

\section{Referências}

1. Vasconcelos, L. M. R., Oliveira, M.V., Graça, M. L. A, Vasconcellos, L. G. O. Carvalho, Y. R., Cairo, C. A. A. Materials Research, vol. 11, n 3, (2008) $275-280$

2. Blom, A. Current Orthopaedics, Vol. 21, (2007), pp. 280-287

3. Caram, R., 2009. "Unicamp desenvolve ligas de titânio". 10 junho. $2009<$ http://blog.projetistasbrasil.com>.

4. Taddei, E. B., Henriques, V. A. R., Silva, C. R. M., Cairo, C. A. A. Revista Brasileira de vácuo, vol. 23, n 2,(2004) 67-72.

5. Alves Jr., C.; Hajek, V.; dos Santos, C. A. Materials sci. and Engineering A., vol.348, (2003) p. $84-89$.
6. Souza jr, C.F.; Sinka, v.; Alves jr, C.; Hajek, V. Anais do Congresso Brasileiro de Ciência e Engenharia de Materiais, Vol.1, Natal, Brasil, 2002.

7. Galvão, N.K.A.M.; Costa, B.L.S.; Mendes, M.W.D.; de Brito, R.A.; Souza Jr. C.F; Alves Jr., C. Journal of Materials Processing Technology, Vol. 200, Issues 1-3, (2008) p. 115-119.

8. Machado, J. L. M., Benderovics, G., Santos, L. A. Anais do Congresso Brasileiro de Ciência e Engenharia de Materiais, Vol.1, Foz do Iguaçu, Brasil, 2006. 